\title{
Clinical features and aetiology of cerebral palsy in children from Cross River State, Nigeria
}

\author{
Roseline Duke, ${ }^{1,2}$ Chimaeze Torty, ${ }^{3}$ Kennedy Nwachukwu, ${ }^{2}$ Soter Ameh, ${ }^{4}$ Min Kim, ${ }^{1}$ \\ Nnena Eneli, ${ }^{5}$ Ani Onyedikachi, ${ }^{5}$ Ada Aghaji, ${ }^{1}$ Kathryn Burton, ${ }^{6}$ Leigh Dyet, ${ }^{7}$ \\ Richard Bowman ${ }^{1}$
}

\begin{abstract}
${ }^{1}$ International Centre for Eye Health, London School of Hygiene and Tropical Medicine, London, United Kingdom ${ }^{2}$ Department of Ophthalmology, Calabar Children's Eye Centre, University of Calabar Teaching Hospital, Calabar, Cross River State, Nigeria

${ }^{3}$ Department of Paediatrics, University of Calabar Teaching Hospital, Calabar, Nigeria ${ }^{4}$ Department of Community Medicine, University of Calabar Teaching Hospital, Calabar, Nigeria

${ }^{5}$ Department of Physiotherapy, University of Calabar Teaching Hospital, Calabar, Nigeria ${ }^{6}$ Cambridge Community Services, Cambridge, UK 7 Neonatology, University College London, London, UK
\end{abstract}

\section{Correspondence to}

Dr Roseline Duke

Ophthalmology, University of Calabar Teaching Hospital,

Calabar, Cross River State 540001, Nigeria;

Roseline.Duke@lshtm.ac.uk

Received 18 July 2019 Revised 16 December 2019 Accepted 18 December 2019 Published Online First 20 January 2020

\section{Check for updates}

(C) Author(s) (or their employer(s)) 2020. No commercial re-use. See rights and permissions. Published by BMJ.

To cite: Duke $R$, Torty $C$,

Nwachukwu K, et al.

Arch Dis Child

2020:105:625-630.

\section{ABSTRACT}

Objective There are few studies on cerebral palsy (CP) in African children and our study aimed to describe the aetiology, characteristics and severity of CP in children from Nigeria.

Design A population-based study using key informant methodology (KIM) was conducted as part of a clinical research trial. Children aged 4-15 years were clinically assessed for $C P$

Results The estimated prevalence of CP using KIM was $2.3 / 1000$ children $(95 \% \mathrm{Cl} 2.0$ to 2.5/1000). 388 children were diagnosed with $\mathrm{CP}$, with Gross Motor Function Classification System level 1 in 70 (18.1\%), II in 156 (40.2\%), III in 54 (13.9\%), IV in 54 (13.9\%), $V$ in 54 (13.9\%). 300/388 (77.3\%) had Manual Ability Classification Scale of level $1-3$ and $88(22.7 \%)$ of level 4-5. CP types were spastic in 271 (70\%), with $60 \%$ of these bilateral and $40 \%$ unilateral, ataxic 38 (9.8\%), dystonic 18 (4.6\%), choreoathetoid $29(7.5 \%)$ and unclassifiable 32 (8.3\%). Postneonatal risk factors for CP were seen in 140 (36.1\%) children including malaria with seizures $101 / 140(72.1 \%)$, malaria with coma $21 / 140$ (15.0\%), meningitis 12/140 (8.6\%), tuberculosis $2 / 140(1.4 \%)$, sickle cell disease $3 / 140$ (2.2\%), HIV 1/221 (0.7\%). Prenatal/perinatal risk factors were seen in $248(63.9 \% \%)$, birth asphyxia $118(47.6 \%)$ and clinical congenital rubella syndrome 8 (3.3\%) and hyperbilirubinaemia 59 (23.8\%) were identified as preventable risk factors for $\mathrm{CP}$.

Conclusion The profile of $C P$ in this population is similar to that found in other low-income and middleincome countries (LMIC). Some risk factors identified were preventable. Prevention and management strategies for CP designed for LMIC are needed.

\section{OBJECTIVE}

Cerebral palsy (CP) is a leading cause of childhood disability across the world with significant impact on function and development. CP refers to a heterogeneous group of conditions involving permanent non-progressive central motor dysfunction that affects muscle tone, posture and movement. The prevalence of CP is approximately 2.11/1000 live births in high-income countries (HIC), with a higher estimated prevalence of 3.4-10/1000 children in LMIC and 1.8-2.3/1000 children in Africa. ${ }^{1-3}$

Several factors may influence the prevalence of $\mathrm{CP}$ in Africa, including the level of maternal or child healthcare and the neonatal morbidity rates in study areas. ${ }^{45} \mathrm{CP}$ results from a variety of insults to the immature, developing brain. The aetiology is
What is already known on this topic?

Data on prevalence and type of cerebral palsy $(\mathrm{CP})$ in sub-Saharan Africa are lacking.

- Key informant methodology (KIM) has successfully been used to provide such data in Bangladesh.

- A recent population-based survey of CP in Uganda found a prevalence of 2.9/1000 children.

\section{What this study adds?}

- The use of KIM to identify children with CP in Nigeria is feasible, which has implications for research and service provision and delivery.

- This study yielded a prevalence estimate of 2.3 (95\% Cl 2.0 to 2.5 ) per 1000 children within this region of Nigeria.

- Preventable risk factors for CP in these Nigerian children were identified including hyperbilirubinaemia and congenital rubella.

multifactorial, and may depend on socioeconomic factors. Prenatal and perinatal risk factors in HIC include low birth weight, preterm birth and multiple pregnancy. ${ }^{6}$ In LMIC, they include maternal infections, neonatal jaundice, neonatal convulsions and infections, birth asphyxia and increasingly, prematurity. ${ }^{45}$ Population-based studies on prevalence and aetiology of CP in Africa are scarce. However, understanding the pathophysiology of $\mathrm{CP}$ in a population is crucial to developing some protective strategies. There is an increasing recognition of the importance of determining the impact of neonatal morbidity on long-term neurological impairment in LMIC.

The aim of this study was to describe the prevalence, characteristic features of $\mathrm{CP}$ including the aetiology/risk factors and severity in this population of Nigerian children, to guide service planning and prevention strategies.

\section{Design}

A cross-sectional study was conducted in Cross River State (CRS) in Nigeria between December 2017 and July 2018. 


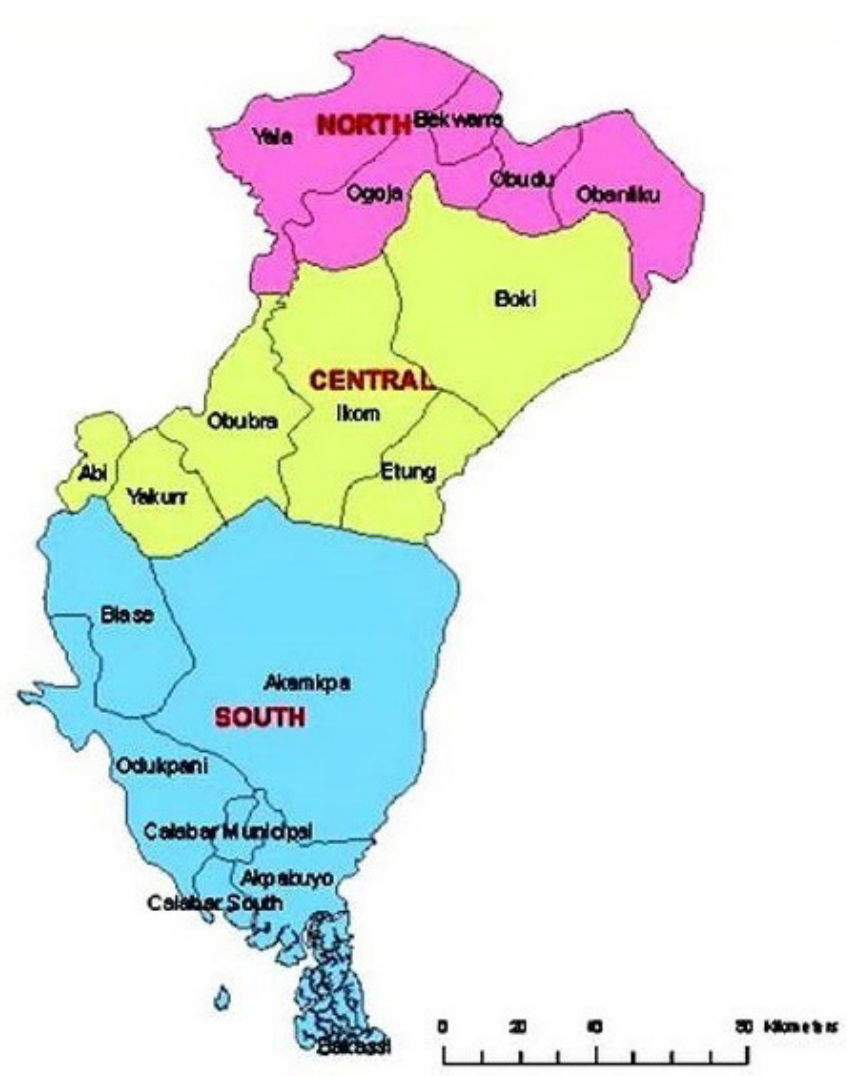

Figure 1 Map of Cross River State, Nigeria showing 3 senatorial districts and 18 local government areas. Courtesy of Osadebamwen Anthony Ogbeide.

\section{Setting}

Eighteen local government areas in three districts (Southern, Central and Northern) that cover an area of $20156 \mathrm{~km}$ in CRS were included in the study (Figure 1). The 2016 population projection for CRS was about 3.87 million with about 1.1 million children aged $<14$ years. Nine communities in three local government areas including: Odukpani (3 communities out of 13, Bakkasi (4 communities out of 13) and Ogoja (2 communities out of 10) with an estimated population of 150000 children were not accessible for security reasons. The demographic and health data for Nigeria report that children between the ages of 5 and 14 years account for $29.2 \%$ of the total population. ${ }^{8}$ The tertiary hospital in CRS is located in the southern senatorial district. Two local government areas in the southern senatorial districts are urban and others rural.

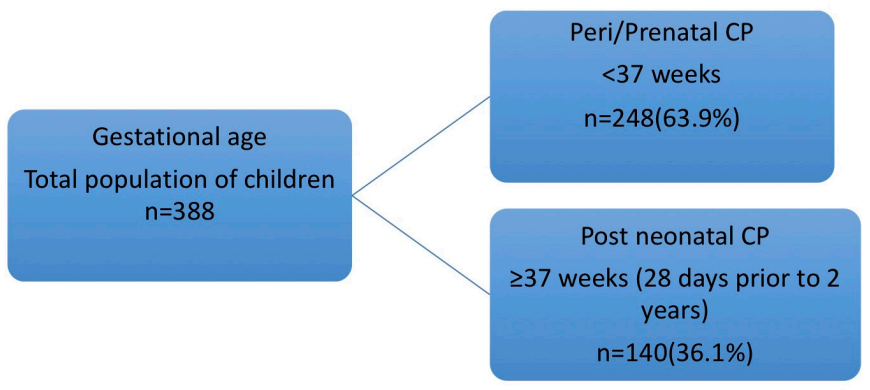

Figure 2 The timing of brain injury/insult/maldevelopment in children with cerebral palsy (CP).

\section{Recruitment}

Children with possible $\mathrm{CP}$ from the nine accessible regions of CRS were identified initially through key informant methodology (KIM). KIM was chosen recognising its effectiveness for identifying physical impairment compared with household survey in LMIC. ${ }^{9}$ Key informants (KI) were local volunteers, all of them secondary school graduates, non-medical personnel, who lived and/or worked in their local community for at least 1 year, who knew the local context and community. They were identified in each community by the village council and were trained to identify children with CP by using a locally produced picture manual developed specifically for the study for case identification with description of CP, and supplemented by the Ten Question Questionnaire to identify suspected cases. ${ }^{10}$ These $\mathrm{KI}$ were given day-long structured training on $\mathrm{CP}$ and group sessions on awareness raising and disability-specific information using flip chart illustrations and role play with guidance from the principal investigator. The children identified by the KI were offered a consultation by a paediatric neurologist to provide an opportunity for diagnosis, treatment and referral of their child. Various search methods were used including house-to-house visits, school and church visits, also village and market place announcements. Cases suspected to have $\mathrm{CP}$ by the KI were brought to a primary health centre in each local government area (LGA).

Team members were trained in using the research protocol form (ie, data collection form which included sociodemographic details, mothers' antenatal history, prenatal, perinatal and postneonatal factors). All the children referred by the KI were assessed to determine if they met the inclusion criteria for the CP register. Families were provided with appropriate advice, information and counselling, referral services and intervention where appropriate.

\section{Participants}

Children aged between 4 and 15 years of age, who were confirmed to have CP from history and clinical assessment by a paediatric neurologist were included in the study and categorised as $<9$ years or $\geq 9-15$ years. Informed consent was taken. Children who had other motor disorders apart from CP and children outside the age criteria were excluded.

\section{Clinical assessment}

The diagnosis of $\mathrm{CP}$ was based on the history, and clinical examination in line with international criteria. ${ }^{2} \mathrm{CP}$ was characterised clinically and by abnormal pattern of movement and posture with additional features, using the Surveillance of Cerebral Palsy in Europe Classification. ${ }^{11}$ Functional status was categorised with respect to motor activity using the Gross Motor Function Classification System (GMFCS) for CP and the Manual Ability Classification System (MACS). ${ }^{12}$

\section{Aetiology and risk factors}

The timing of the brain injury was classified as postneonatal, when there was a clear history from the caregiver of the child having been well until 28 days and then having suffered some event between the ages of 28 days and 2 years. In the absence of such a history, the timing was classified as prenatal or perinatal. We identified possible risk factors for prenatal/perinatal aetiology.

\section{Prenatal/Perinatal CP}

Prenatal risk factors might be indicated by an abnormal antenatal history including parental age, maternal drug or alcohol 
use, inconsistent or absent antenatal care, gestational diabetes, maternal infections, multiple gestation and febrile maternal illness. The perinatal period was defined as from $22 \mathrm{nd}$ week of gestation until 4 weeks after birth to allow for uncertainty about timing of events after birth and include events related to birth. ${ }^{13}$ An abnormal perinatal period was defined as any of the following: the need for a non-elective caesarean section, preterm delivery (defined as babies born alive before 37 weeks of pregnancy), assisted delivery (vacuum or forceps), birth asphyxia (clear recollection of child not breathing or gasping at $5 \mathrm{~min}$ or a history of resuscitation), instrument-assisted delivery and antepartum haemorrhage and neonatal jaundice. Neonatal jaundice was not investigated; however, neonatal jaundice was felt to be significant and then referred to as hyperbilirubinaemia in this study if poor suck was noted and the child was hospitalised with jaundice.

\section{Postneonatal-acquired CP}

Post neonatal risk factors in a child in whom there was an incident of any of the following was present: convulsions, systemic infection and admissions for whatever cause to the neonatal unit. Postneonatal causes were from the period following 28 days prior to 2 years after birth and included malaria with seizures or coma, meningoencephalitis, heamoglobinopathy and identified HIV infection.

Congenital HIV (though perinatally acquired) would be likely to cause a brain injury postneonatally (through secondary infection) and likewise haemoglobinopathy such as sickle cell disease (though congenital) would be postneonatal CP since strokes associated with this tend to be postneonatal.

The standard definitions for preterm birth, prolonged labour and microcephaly were used. ${ }^{14}$ Clinical congenital rubella syndrome was diagnosed by signs of any two classic features without a more plausible aetiology (congenital heart disease, microcephaly, cataract or glaucoma, deafness and pigmentary retinopathy). ${ }^{1516}$

This study was part of a clinical trial and considering the population size for children as 1.1 million, a $10 \%$ non-response rate and an assumed prevalence of CP of 2.9 per 1000 (0.0029), a sample size of 370 would yield a prevalence precision level of $0.58 \%$.

\section{Statistical analysis}

Statistical analyses were performed using Stata V.15 (StataCorp, College Station, Texas, USA). Descriptive statistics were reported using means and SD for normally distributed variables, medians and IQRs for non-normally distributed continuous variables and frequencies and percentages for categorical variables. Comparisons between categorical variables were performed using a $\chi^{2}$ test or Fisher's exact test, and t-test was used for continuous variables. The estimated prevalence of children with $\mathrm{CP}$ in this population was derived by dividing the number of cases confirmed to have CP 4-15 years by the estimated total number of children aged 4-15 years in the population from the communities included in this study. Significance level was set at $\mathrm{p}<0.05$. Variables of interest occurred in at least $30 \%$ of subjects and missing data were included.

\section{RESULTS}

KI identified 1024 children, 293 (28.6\%) were not brought for examination, $343(33.5 \%)$ did not have CP (table 1) and 388 (37.9\%) were confirmed to have CP. The estimated population prevalence of CP in children between 4 and 15 years using KIM is $2.3 / 1000(388 / 171200 ; 95 \%$ CI 2.0 to $2.5 / 1000)$.

\section{Sociodemography}

There were no missing data in the variables of interest.

Table 2 describes the sociodemographic information of the children with CP $(n=388)$. The mean age was 9.2 years (SD 4.0). One-third of children were first born $(133 / 388,34.3 \%)$. Less severe GMFCS was seen in the older age group 172/212 (81\%) compared with the younger group 108/176 (61\%); $\mathrm{p}<0.001$.

Standard vaccines (BCG, oral polio vaccine, diphtheria pertussis tetanus, Haemophilus influenzae, measles) were not administered at all in 3/388 (1\%) children. In 63/388 (16.24\%) children, uptake of immunisation was incomplete, and this rate was not significantly different between the rural and urban areas. Six $(2 \%)$ children had not received doses 1 and 2 of vitamin A supplementation. Rubella immunisation is not given in Nigeria.

\section{CP description}

Spastic CP was the most common type (271/388,69.9\%), and was bilateral in 163/271 (60.2\%) and unilateral in 108 (39.8\%). Table 3 shows a clinical description of CP motor types, spastic topography, levels of GMFCS and MACS and the proportions of perinatal/prenatal and postneonatal risk factors. GMFCS levels were categorised as levels I-III $(\mathrm{n}=280,72.2 \%)$ and levels IV-V ( $\mathrm{n}=108,27.8 \%)$. MACS levels were: 1, 178 (45.9\%); 2, 75 (19.3\%); 3, 47 (12.1\%); 4, 80 (20.6\%); 5, 8 (2.1\%). Children with MACs levels 4-5 77/108 (71.3\%) versus MACS level 1-3 31/108 (28.7\%) were associated with GMFCS level IV-V 108/388 (27.8\%); (p<0.001).

More children with spastic CP and fewer with choreoathetoid CP had higher levels of motor difficulties as on GMFCS (table 4).

\section{Aetiology}

Timing of causal brain injury was deduced to be postneonatal in $140 / 388(36.1 \%)$ and perinatal/prenatal in $248 / 388(63.9 \%)$ (figure 2 and table 3).

Postneonatal risk factors include: malaria with seizures $101 / 140$ (72.1\%), malaria with coma 21/140 (15.0\%), meningitis $12 / 140(8.6 \%)$, tuberculosis $2 / 140(1.4 \%)$, sickle cell disease 3/140 (2.2\%), HIV 1/221 (0.7\%).

Prenatal/perinatal risk factors included maternal age; then mean age was $33.6 \pm 8.8,32(28,40), 63 / 103(61.2 \% ; p=0.497)$ were $>38$ years. The mean age of fathers was $40.9 \pm 40(34,50)$, $115 / 171(67.3 \% ; \mathrm{p}=0.225)$ were older than 40 years. Twin births were seen in $5 / 248(2.0 \%)$, birth asphyxia in $118 / 248(47.6 \%)$ and hyperbilirubinaemia in 59/248 (23.8\%). Of those that developed hyperbilirubinaemia, 11/29 (37.9) were children with choreoathetoid CP versus other types of CP 48/359 (13.4\%); $\mathrm{p}=0.002$. Of the total number of children with choreoathetoid CP, 10/29 (34.5\%); $p=0.782$ were first born children. Eight children $(3.3 \%)$ met the criteria for clinical congenital rubella syndrome. Premature birth was reported in 20/248 (8.1\%) and unknown factors in 38/248 (15.3\%) children.

\section{DISCUSSION}

The prevalence estimate of CP in this population was close to other estimates from similar populations in Africa. ${ }^{2}$ KIM methodology was chosen because it offers a low-cost, relatively rapid method to identify children with CP in an LMIC, as extensively reported in Bangladesh. ${ }^{3}$ The clinical diagnoses of non-CP cases were also similar to other African studies (table 1). ${ }^{2}$ Our 
Table 1 Diagnoses of children referred by key informants with noncerebral palsy diagnosis

\begin{tabular}{|c|c|}
\hline Variables & $\mathrm{N}$ \\
\hline \multicolumn{2}{|l|}{ Age } \\
\hline Mean (SD) & 8.98 \\
\hline Male & 206 \\
\hline Female & 137 \\
\hline \multicolumn{2}{|l|}{ Infections } \\
\hline Postmeningitis sequelae & 6 \\
\hline Polio & 1 \\
\hline \multicolumn{2}{|l|}{ Neurological/sensory problems } \\
\hline Intellectual difficulty & 53 \\
\hline Speech impairment & 76 \\
\hline Epilepsy & 35 \\
\hline Hearing impairment & 42 \\
\hline Behavioural disorder & 7 \\
\hline Strabismus & 3 \\
\hline Visual impairment & 2 \\
\hline \multicolumn{2}{|l|}{ Congenital deformities } \\
\hline Down syndrome & 102 \\
\hline Clubfoot & 33 \\
\hline Microcephaly & 3 \\
\hline Congenital multiple limb malfunction & 3 \\
\hline Congenital equino virus & 2 \\
\hline Congenital knee amputation & 1 \\
\hline Mesomelia & 1 \\
\hline \multicolumn{2}{|l|}{ Heamoglobinopathies } \\
\hline Sickle cell anaemia & 7 \\
\hline \multicolumn{2}{|l|}{ Nutrition } \\
\hline Rickets & 3 \\
\hline \multicolumn{2}{|l|}{ Trauma } \\
\hline Spinal cord injury & 1 \\
\hline Injection palsy & 1 \\
\hline Fracture of the bone & 1 \\
\hline Total & $383^{*}$ \\
\hline
\end{tabular}

*383 diagnoses were made even though 343 children were examined. This is because some children had multiple associated conditions and more than one diagnosis (speech, hearing, intellectual difficulty and visual impairments). Therefore, the total number of diagnosis made exceeds the number of children seen. estimated prevalence was slightly lower than the Ugandan study (2.3 vs 2.7/1000) and the recent study from Bangladesh (2.3 vs 3.4/1000), but our study involved older children and early mortality may therefore act to reduce our recorded prevalence. We are also aware of stigma associated with public appearance of children with CP, which could result in under-reporting, through KIM methodology versus a door-to-door sampling method. ${ }^{17} \mathrm{~A}$ potential advantage of KIM methodology is that it also provides the opportunity to plan interventions using a community-centred approach which encourages access to health services.

$\mathrm{CP}$ prevalence in this setting may be related to other indicators of poor health in the country such as the high incidence of maternal and neonatal morbidity. It is suggested that for over $80 \%$ of CP the cause/causal pathway remains unknown. ${ }^{18}{ }^{19}$ In this population, the timing of the risk factors for CP during the postneonatal period appears to be associated with preventable causes and was of a high proportion. We saw that there was an association between rural and prenatal/perinatal risk factors for CP. This may be as a result of inadequate and poor quality health facilities in rural areas where, for example, prolonged labour with the consequence of birth asphyxia is common. ${ }^{20} \mathrm{In}$ LMIC, hyperbilirubinaemia with bilirubin encephalopathy is a significant cause of neonatal neurodevelopmental morbidity and is a priority for effective intervention strategies. ${ }^{21} \mathrm{~A}$ number of studies have reported that many mothers delay seeking timely and appropriate care. ${ }^{22}$ Strategic health education for mothers on early identification of symptoms of hyperbilirubinaemia may promote earlier presentation and effective intervention.

Symptoms of birth asphyxia were seen in about one-third of cases of CP, which may be significant suggesting improved antenatal and perinatal care could improve outcomes. However, the direct contribution of adverse intrapartum and obstetric events to overall CP rate is thought to be less than suggested by overall occurrence of birth asphyxia symptoms. ${ }^{23-25}$ The causal pathway model highlights that there are likely to be a network of earlier risk factors for $\mathrm{CP}$ such as maternal infection and poor placental function, which may lead to later presentation with symptoms of birth asphyxia and CP. Understanding the network of factors that contribute to the causal pathway may identify points for intervention and promote prevention rather than ameliorating the injury. ${ }^{25}$

Perinatal/Prenatal aetiologies are difficult to ascertain accurately from observational studies, and true ascertainment about

Table 2 Sociodemographic characteristics of children with cerebral palsy $(n=388)$

\begin{tabular}{|c|c|c|c|c|c|c|c|c|}
\hline Characteristic & $\mathrm{N}$ & $\%$ & $\begin{array}{l}\text { GMFCS I-III, } \\
(n, \%)\end{array}$ & $\begin{array}{l}\text { GMFCS } \\
\text { IV-V } \\
(n, \%)\end{array}$ & $P$ value & $\begin{array}{l}\text { Perinatal/Prenatal } \\
\text { CP } \\
(n, \%)\end{array}$ & $\begin{array}{l}\text { Postnatal CP } \\
(n, \%)\end{array}$ & $P$ value \\
\hline Total & 388 & 100 & $280(72.2)$ & $108(27.8)$ & & $248(63.9)$ & $140(36.08)$ & \\
\hline \multicolumn{9}{|l|}{ Residence } \\
\hline Urban & 44 & 11.3 & $33(11.8)$ & $11(10.2)$ & 0.656 & $36(14.52)$ & $8(5.7)$ & \\
\hline Rural & 344 & 88.7 & $247(88.2)$ & $97(89.8)$ & & $212(85.5)$ & $132(94.3)$ & 0.009 \\
\hline \multicolumn{9}{|l|}{ Demographic } \\
\hline \multicolumn{9}{|l|}{ Sex } \\
\hline Male & 229 & 59.0 & $168(60)$ & $61(56.5)$ & 0.528 & $148(59.7)$ & $81(57.9)$ & 0.726 \\
\hline Female & 159 & 41.0 & $112(40)$ & $47(43.5)$ & & $100(40.3)$ & $59(42.1)$ & \\
\hline \multicolumn{9}{|l|}{ Age } \\
\hline Mean (SD) & 9.2 & 4.0 & & & & & & \\
\hline Median (IQR) & 9 & 6,13 & & & & & & \\
\hline$<9$ years & 176 & 45.4 & $108(38.6)$ & $68(63.0)$ & $<0.001$ & $113(64.2)$ & $63(45)$ & 0.915 \\
\hline $9+$ years & 212 & 54.6 & $172(61.4)$ & $40(37.0)$ & & $135(63.7)$ & $77(55.0)$ & \\
\hline
\end{tabular}

GMFCS, Gross Motor Function Classification System. 


\begin{tabular}{|c|c|c|c|}
\hline $\begin{array}{l}\text { CP motor types and } \\
\text { spastic topography }\end{array}$ & N (\%) & $\begin{array}{l}\text { Perinatal/Prenatal } \\
\text { CP N }(\%)\end{array}$ & $\begin{array}{l}\text { Postnatal CP } \\
\mathrm{N}(\%)\end{array}$ \\
\hline \multicolumn{4}{|l|}{ CP motor type } \\
\hline Spastic CP & $271(69.9)$ & $167(67.3)$ & $104(74.3)$ \\
\hline Bilateral spastic & $163(60.2)$ & & \\
\hline Unilateral spastic & $108(39.8)$ & & \\
\hline Ataxic CP & $38(9.8)$ & $28(73.7)$ & $10(26.3)$ \\
\hline Dystonic CP & $18(4.6)$ & $14(77.8)$ & $4(22.2)$ \\
\hline Choreoathetoid CP & $29(7.5)$ & $20(69)$ & $9(31.0 \%)$ \\
\hline Unclassifiable CP & $32(8.3)$ & 19 (59.4) & $13(40.6)$ \\
\hline Total & $388(100)$ & $248(63.9)$ & $140(36.1)$ \\
\hline \multicolumn{4}{|l|}{ GMFCS } \\
\hline I & 70 (18) & $52(21)$ & $18(12.9)$ \\
\hline II & $156(40)$ & $95(38.3)$ & $61(43.6)$ \\
\hline III & $54(14)$ & $31(12.5)$ & $23(16.4)$ \\
\hline IV & $54(14)$ & $36(14.5)$ & $18(12.9)$ \\
\hline V & $54(14)$ & 34 (13.7) & $20(14.3)$ \\
\hline \multicolumn{4}{|l|}{ MACS } \\
\hline 1 & $178(45.9)$ & $111(44.8)$ & 67 (47.9) \\
\hline 2 & $75(19.3)$ & $48(19.3)$ & 27 (19.3) \\
\hline 3 & $47(12.1)$ & $32(12.9)$ & $15(10.7)$ \\
\hline 4 & $80(20.6)$ & $51(20.6)$ & $29(20.7)$ \\
\hline 5 & $8(2.06)$ & $6(2.4)$ & $2(1.4)$ \\
\hline
\end{tabular}

CP, cerebral palsy; GMFCS, Gross Motor Function Classification Scale; MACS, Manual Ability Classification Scale.

whether the primary cause is prenatal or perinatal is challenging in this type of study. However, recognising potentially contributory factors in this setting is important for targeting prevention strategies. Another likely preventable cause was congenital rubella syndrome, which is one of the leading vaccine-preventable causes of birth defects. Vaccines have been shown to have significantly decrease the incidence of congenital rubella syndrome in HIC and possibly the contribution to the incidence of CP. As neonatal care in LMIC improves, multiple pregnancies and prematurity may become more common as risk factors for CP.

We noted also that a small percentage of children with $\mathrm{CP}$ were either not immunised at all (1\%) or did not have full immunisation uptake (16\%), similar to other studies in Australia and Turkey. ${ }^{26}$ Further research is needed into the factors that

Table 4 Pearson's $X^{2}$ test, CP motor types and spastic topography of CP vs GMFCS level

\begin{tabular}{llllll}
\hline \multicolumn{5}{c}{ GMFCS I-III IV-V } \\
CP motor types & $\mathbf{N}(\%)$ & $\begin{array}{l}\text { GMFCS } \\
(\mathbf{n}, \%)\end{array}$ & $\mathbf{X}^{2}$ & P value \\
\hline Total observations & $388(100)$ & $280(72.2)$ & $108(27.8)$ \\
\hline Type of CP & & & \\
\hline Spastic CP & $271(69.9)$ & $178(65.7)$ & $93(34.3)$ & 18.8 & $<0.001$ \\
\hline \multicolumn{1}{c}{ Bilateral spastic } & $163(60.2)$ & & & & \\
\hline \multicolumn{1}{c}{ Unilateral spastic } & $108(39.8)$ & & & & \\
Ataxic CP & $38(9.8)$ & $36(94.7)$ & $2(5.3)$ & 10.7 & $<0.001$ \\
\hline Dystonic CP & $18(4.6)$ & $16(88.9)$ & $2(11.1)$ & 2.6 & 0.105 \\
\hline Choreoathetoid CP & $29(7.5)$ & $23(79.3)$ & $6(20.7)$ & 0.8 & 0.372 \\
\hline Unclassifiable CP & $32(8.3)$ & $27(84.2)$ & $5(16.6)$ & 2.6 & 0.08 \\
\hline
\end{tabular}

$\mathrm{CP}$, cerebral palsy; GMFCS, Gross Motor Function Classification Scale influence uptake of full immunisation in children with $\mathrm{CP}$ and to identify barriers and enablers to accessing vaccination.

The physical characteristics of CP in this population showed similar distribution in type, GMFCS, MACS, to those seen in other LMIC. ${ }^{28}$ Less severe GMFCS was seen in the older age group compared with the younger, suggesting a higher mortality at an early age in those with the highest GMFCS as seen in similar LMIC studies. ${ }^{32}$

The study was conducted in one state in the country which has a higher socioeconomic index compared with the rest of the country, and the prevalence of CP was an estimate by KIM, making it difficult to generalise for the whole country or region. Likewise, security problems restricted access to nine communities in the study area which could also introduce bias, and reduced access in these troubled areas to maternal and neonatal healthcare could also affect prevalence of CP. Sources of inaccuracy include KIM (selection bias) and likely stigma limiting the number of children brought forward for assessment. Judgement about aetiology and risk factors are likely to have been affected by recall bias and the unavailability of neuroimaging which oftentimes aids understanding of the timing of injury. In spite of these limitations, the study used trained personnel as interviewers, international protocols and classifications and represents a large sample of children with CP.

\section{Interpretation}

The profile of CP in this community-based study in Nigeria is similar to that in LMIC and one with potential associations with preventable neonatal conditions such as hyperbilirubinaemia, congenital rubella and likely birth asphyxia. There is a need to focus on primary prevention strategies for these common causes of neonatal morbidity and to provide holistic care.

Acknowledgements The authors would like to thank all the carers of children with CP and the key informants who participated in this study.

Contributors RD: conceived the idea and design of the study, primary author (drafted and edited the paper), data collection. CT: data collection. MK: data analysis and interpreter. SA: provided access to crucial research components and data interpretation. NE: data collection. AO: data collection. AA: data collection. KB: conceived the design of the study, provided revisions to grammar/scientific content of manuscript. RB: principal investigator (advisor, head of research) conceived the idea and design of the study, provided revisions to grammar/scientific content of manuscript. All authors contributed equally to this research work. All authors provided substantial contributions to the conception or design of the work; or the acquisition, analysis or interpretation of data for the work; drafting the work or revising it critically for important intellectual content; final approval of the version to be published; agreement to be accountable for all aspects of the work in ensuring that questions related to the accuracy or integrity of any part of the work are appropriately investigated and resolved

Funding The Queen Elizabeth Diamond Jubilee Trust/Common Wealth Eye Health Consortium funded the research grant number (LSHTM ITCRZ6814).

Competing interests None declared.

\section{Patient consent for publication Not required.}

Ethics approval The study was approved by the London School of Hygiene and Topical Medicine and the Cross River State, health research and ethics committee with number CRS/MH/HREC/015/Vol.211.

Provenance and peer review Not commissioned; externally peer reviewed.

Data availability statement Data are available on reasonable request.

\section{REFERENCES}

1 Donald KA, Samia P, Kakooza-Mwesige A, et al. Pediatric cerebral palsy in Africa: a systematic review. Semin Pediatr Neurol 2014;21:30-5.

2 Kakooza-Mwesige A, Andrews C, Peterson S, et al. Prevalence of cerebral palsy in Uganda: a population-based study. Lancet Glob Health 2017;5:e1275-82.

3 Khandaker G, Muhit M, Karim T, et al. Epidemiology of cerebral palsy in Bangladesh: a population-based surveillance study. Dev Med Child Neurol 2019;61:601-9. 
4 Bearden DR, Monokwane B, Khurana E, et al. Pediatric Cerebral Palsy in Botswana: Etiology, Outcomes, and Comorbidities. Pediatr Neurol 2016;59:23-9.

5 Gladstone M. A review of the incidence and prevalence, types and aetiology of childhood cerebral palsy in resource-poor settings. Ann Trop Paediatr 2010;30:181-96.

6 Pakula AT, Van Naarden Braun K, Yeargin-Allsopp M. Cerebral palsy: classification and epidemiology. Phys Med Rehabil Clin N Am 2009;20:425-52.

7 Blencowe H, Vos T, Lee ACC, et al. Estimates of neonatal morbidities and disabilities at regional and global levels for 2010: introduction, methods overview, and relevant findings from the global burden of disease study. Pediatr Res 2013;74:4-16.

8 National Malaria Elimination Programme (NMEP) NPCN, National Bureau of Statistics (NBS), and ICF International. Nigeria Malarai indicator. Abuja, Nigeria, and Rockville, Maryland, USA: NMEP, NPopC, and ICF International, 2015.

9 Khandaker G, Smithers-Sheedy H, Islam J, et al. Bangladesh cerebral palsy register $(\mathrm{BCPR})$ : a pilot study to develop a national cerebral palsy (CP) register with surveillance of children for CP. BMC Neurol 2015:15:173.

10 Mung'ala-Odera V, Meehan R, Njuguna P, et al. Validity and Reliability of the 'Ten Questions' Questionnaire for Detecting Moderate to Severe Neurological Impairment in Children Aged 6-9 Years in Rural Kenya. Neuroepidemiology 2004;23:67-72.

11 Surveillance of Cerebral Palsy in Europe. Surveillance of cerebral palsy in Europe: a collaboration of cerebral palsy surveys and registers. Dev Med Child Neurol 2000;42:816-24.

12 Gunel MK, Mutlu A, Tarsuslu T, et al. Relationship among the manual ability classification system (MACS), the gross motor function classification system (GMFCS), and the functional status (WeeFIM) in children with spastic cerebral palsy. Eur J Pediatr 2009;168:477-85.

13 Tyson JE, Gilstrap LC. Hope for perinatal prevention of cerebral palsy. JAMA 2003;290:2730-2.

14 Nystedt A, Hildingsson I, Astrid Nystedt IH. Diverse definitions of prolonged labour and its consequences with sometimes subsequent inappropriate treatment. BMC Pregnancy Childbirth 2014;14:233.

15 Lambert SR. Congenital rubella syndrome: the end is in sight. Br J Ophthalmol 2007;91:1418-9.
16 Orenstein WA, Preblud SR, Bart KJ, et al. Methods of assessing the impact of congenital rubella infection. Clinical Infectious Diseases 1985;7:\$22-8.

17 Green SE. "What do you mean 'what's wrong with her?'": stigma and the lives of families of children with disabilities. Soc Sci Med 2003:57:1361-74.

18 Korzeniewski SJ, Slaughter J, Lenski M, et al. The complex aetiology of cerebral palsy. Nat Rev Neurol 2018;14:528-43.

19 Marret S, Vanhulle C, Laquerriere A. Pathophysiology of cerebral palsy. Handb Clin Neurol 2013:111:169-76

20 Dolea CAC. Global burden of obstructed labour in the year 2000 Geneva: World Health organization, 2003. Available: https://www.who.int/healthinfo/statistics/bod_ obstructedlabour.pdf.

21 Olusanya BO OT, Kumar P, Boo NY, et al. Management of late-preterm and term infants with hyperbilirubinaemia in resource-constrained settings. BMC Pediatr 2015:15-39.

22 Olusanya BO, Osibanjo FB, Slusher TM. Risk factors for severe neonatal hyperbilirubinemia in low and middle-income countries: a systematic review and meta-analysis. PLoS One 2015;10:e0117229.

23 Blair E, Stanley FJ. Intrapartum asphyxia: a rare cause of cerebral palsy. J Pediatr 1988:112:515-9.

24 Stavsky M, Mor O, Mastrolia SA, et al. Cerebral Palsy-Trends in epidemiology and recent development in prenatal mechanisms of disease, treatment, and prevention. Frontiers in Pediatrics 2017:5:21.

25 Badawi N, Keogh JM. Causal pathways in cerebral palsy. J Paediatr Child Health 2013;49:5-8.

26 Greenwood VJ, Crawford NW, Walstab JE, et al. Immunisation coverage in children with cerebral palsy compared with the general population. J Paediatr Child Health 2013;49:E137-41.

27 Dinleyici M, Carman KB, Kilic $\mathrm{O}$, et al. The immunization status of children with chronic neurological disease and serological assessment of vaccine-preventable diseases. Hum Vaccin Immunother 2018;14:1970-6.

28 O'Shea M, O'Shea M. Cerebral palsy. Semin Perinatol 2008;32:35-41.

29 Kakooza-Mwesige A, Forssberg H, Eliasson A-C, et al. Cerebral palsy in children in Kampala, Uganda: clinical subtypes, motor function and co-morbidities. BMC Res Notes 2015;8:166 